\title{
Tungsten-Nickel Alloy Boosts Alkaline Hydrogen Evolution Reaction
}

Nana Yang, ${ }^{\dagger,+\perp}$ Zhigang Chen, ${ }^{*},+\perp$ Ding Ding, ${ }^{\dagger}$ Chengfeng Zhu,,++ Xingxing Gan,,$+*$ and $\mathrm{Yi} \mathrm{Cui}^{*}, \dot{\dagger}, \dot{+}$

$\dagger$ Vacuum Interconnected Nanotech Workstation, Suzhou Institute of Nano-Tech and Nano-Bionics, Chinese Academy of Sciences, Suzhou 215123, China

${ }^{\star}$ School of Nano Technology and Nano Bionics University of Science and Technology of China, Hefei 230026, China

${ }^{\perp}$ These authors contributed equally to this work.

*E-mail: zgchen2015@sinano.ac.cn; ycui2015@sinano.ac.cn 


\section{Experimental details:}

Chemicals: Sodium tungstate dehydrate $\left(\mathrm{Na}_{2} \mathrm{WO}_{4} \cdot 2 \mathrm{H}_{2} \mathrm{O}\right.$, AR, Sinopharm Chemical Reagent Co., Ltd.), Nickel(II) chloride hexahydrate $\left(\mathrm{NiCl}_{2} \cdot 6 \mathrm{H}_{2} \mathrm{O}\right.$, AR, Sinopharm Chemical Reagent Co., Ltd.), Urea $\left(\mathrm{H}_{2} \mathrm{NCONH}_{2}\right.$, AR, Enox), Ethylene glycol ( $\mathrm{HOCH}_{2} \mathrm{CH}_{2} \mathrm{OH}, \mathrm{AR}$, General-reagent).

Synthesis of the $\mathrm{WNi}_{4} @ \mathrm{~W}-\mathrm{WO}_{2}$ coated in Ni foam: First, the commercial Ni foam $(1 \mathrm{~cm} \times 3 \mathrm{~cm})$ was successively washed in $0.1 \mathrm{M} \mathrm{HCl}$ solutions and distilled water to remove surface passivation and contaminants. Second, $\mathrm{NiCl}_{2} \cdot 6 \mathrm{H}_{2} \mathrm{O}(7.128 \mathrm{mg}$ ), $\mathrm{Na}_{2} \mathrm{WO}_{4} \cdot 2 \mathrm{H}_{2} \mathrm{O}(9.9 \mathrm{mg})$, and urea $(3.6 \mathrm{mg})$ were dissolved in the mixture of $\mathrm{H}_{2} \mathrm{O}(30$ $\mathrm{mL})$ and ethylene glycol $(30 \mathrm{~mL})$ with continuous stirring at $60{ }^{\circ} \mathrm{C}$ for approximately $2 \mathrm{~h}$. Third, the homogeneous solutions containing $\mathrm{W}$ and Ni precursors and the pretreated Ni foam were transferred to the Teflon autoclave $(100 \mathrm{~mL})$, which was sealed and heated at $160{ }^{\circ} \mathrm{C}$ for $12 \mathrm{~h}$. After the autoclave cooled down to the room temperature, the $\mathrm{NiWO}_{4}$ precursors coated on $\mathrm{Ni}$ foam was obtained. For comparison, the bare $\mathrm{Ni}$ and $\mathrm{WO}_{2}$ samples coated on $\mathrm{Ni}$ foam were also collected following the same method without the addition of $\mathrm{Na}_{2} \mathrm{WO}_{4} \cdot 2 \mathrm{H}_{2} \mathrm{O}$ and $\mathrm{NiCl}_{2} \cdot 6 \mathrm{H}_{2} \mathrm{O}$, respectively. Finally, the hybrid precursors were annealed at $550{ }^{\circ} \mathrm{C}$ under $\mathrm{Ar} / \mathrm{H}_{2}(\mathrm{v}: \mathrm{v}=95: 5)$ atmosphere for $2 \mathrm{~h}$.

Characterization: Transmission electron microscopy (TEM) observations and energy dispersive X-ray spectroscopy (EDX) were performed using a FEI Tecnai G2F20 microscope. To prepare the TEM specimens, a small drop of the specimen solution containing $\mathrm{WNi}_{4} @ \mathrm{~W}-\mathrm{WO}_{2}$ electrocatalysts was mounted on an ultrathin amorphous carbon film supported by a copper grid and then naturally dried in air at ambient temperature. XRD pattern of the synthesized $\mathrm{WNi}_{4} @ \mathrm{~W}-\mathrm{WO}_{2}$ powder scraped from $\mathrm{Ni}$ foam was recorded on a Bruker AXS D8 Advance X-ray diffractometer with a $\mathrm{Cu} \mathrm{Ka}$ radiation target $(40 \mathrm{~V}, 40 \mathrm{~A})$. In situ variable temperature near ambient pressure X-ray photoelectron spectroscopy (NAP-XPS) measurements were performed using a NAPXPS instrument equipped with a temperature-controllable laser heating device. Quasi in situ alkaline HER measurements were conducted on a NAP-XPS connected glovebox system. 
Fabrication of $\mathrm{WNi}_{4} @ \mathrm{~W}-\mathrm{WO}_{2} / \mathrm{GCE}$ and $\mathrm{WNi}{ }_{4} @ \mathrm{~W}-\mathrm{WO}_{2} / \mathrm{C}$ electrodes: $10 \mathrm{mg}$ of the $\mathrm{WNi}_{4} @ \mathrm{~W}-\mathrm{WO}_{2}$ powder was dispersed in a mixture of $800 \mu \mathrm{L}$ ethanol, $170 \mu \mathrm{L}$ water and $30 \mu \mathrm{L}$ nafion, and the homogeneous catalyst ink was obtained by sonication over $30 \mathrm{~min}$. Then, 5 and $70 \mu \mathrm{L}$ of the alloy catalyst ink were dropped onto the GCE (diameter: $3 \mathrm{~mm})$ and carbon film $(1 \times 1 \mathrm{~cm})$ with drying naturally for the following electrocatalytic measurements, respectively.

Electrochemical measurements: The HER performance was performed on a CHI760E electrochemical station (Shanghai Chenhua Co., China) using a standard three-electrode system in $1 \mathrm{M} \mathrm{KOH}$ electrolyte, in which the $\mathrm{WNi}_{4} @ \mathrm{~W}-\mathrm{WO}_{2}$ coated on $\mathrm{Ni}$ foam, $\mathrm{Ag} / \mathrm{AgCl}$ electrode, and a carbon rod were used as working, reference, and counter electrodes, respectively. All the potentials measured against an $\mathrm{Ag} / \mathrm{AgCl}$ electrode have been calibrated with respect to the reversible hydrogen electrode (RHE) according to the equation $\mathrm{E}_{\mathrm{RHE}}=\mathrm{E}_{\mathrm{Ag} / \mathrm{AgCl}}+0.197+0.059 \times \mathrm{pH}$.
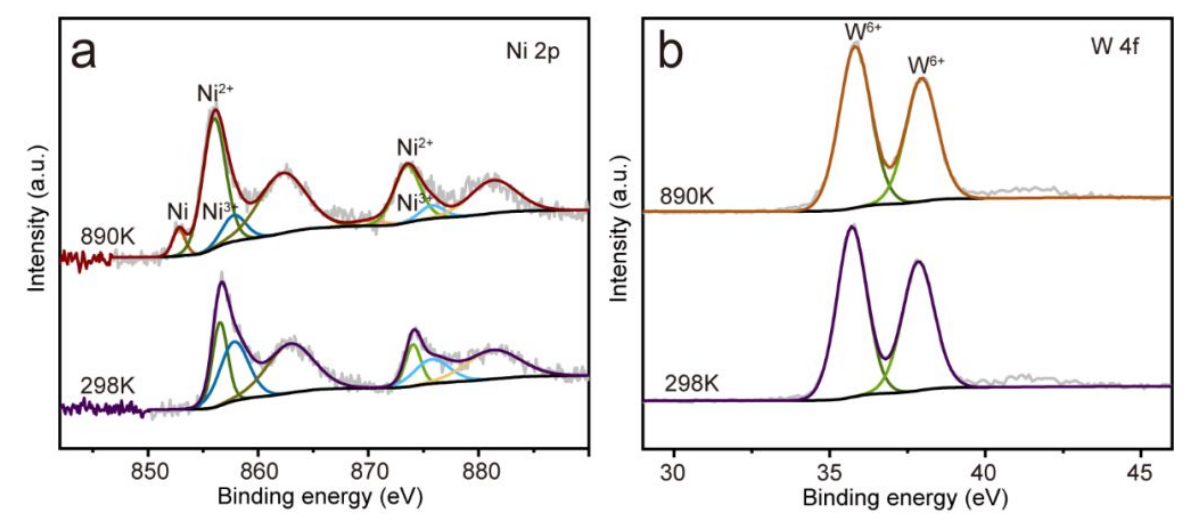

Figure S1. Ni $2 \mathrm{p}$ and $\mathrm{W} 4 \mathrm{f}$ core level XPS spectra of $\mathrm{NiWO}_{4}$ before and after calcination under pure $\mathrm{Ar}$ atmosphere, the weak signal of $\mathrm{Ni}^{0}$ and high valence-state $\mathrm{W}$ species indicate the vital role of hydrogen gas in the synthesis of $\mathrm{WNi}_{4}$ alloy. 

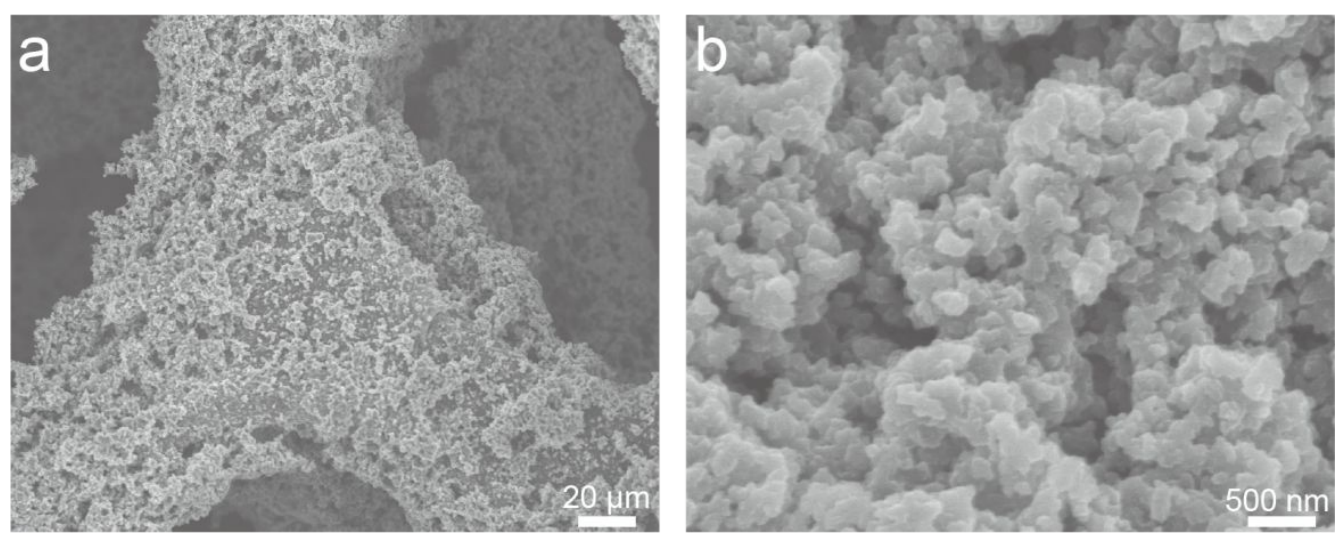

Figure S2. (a) Low- and (b) high-magnification SEM images of W-Ni nanohybrids coating on $\mathrm{Ni}$ foam.

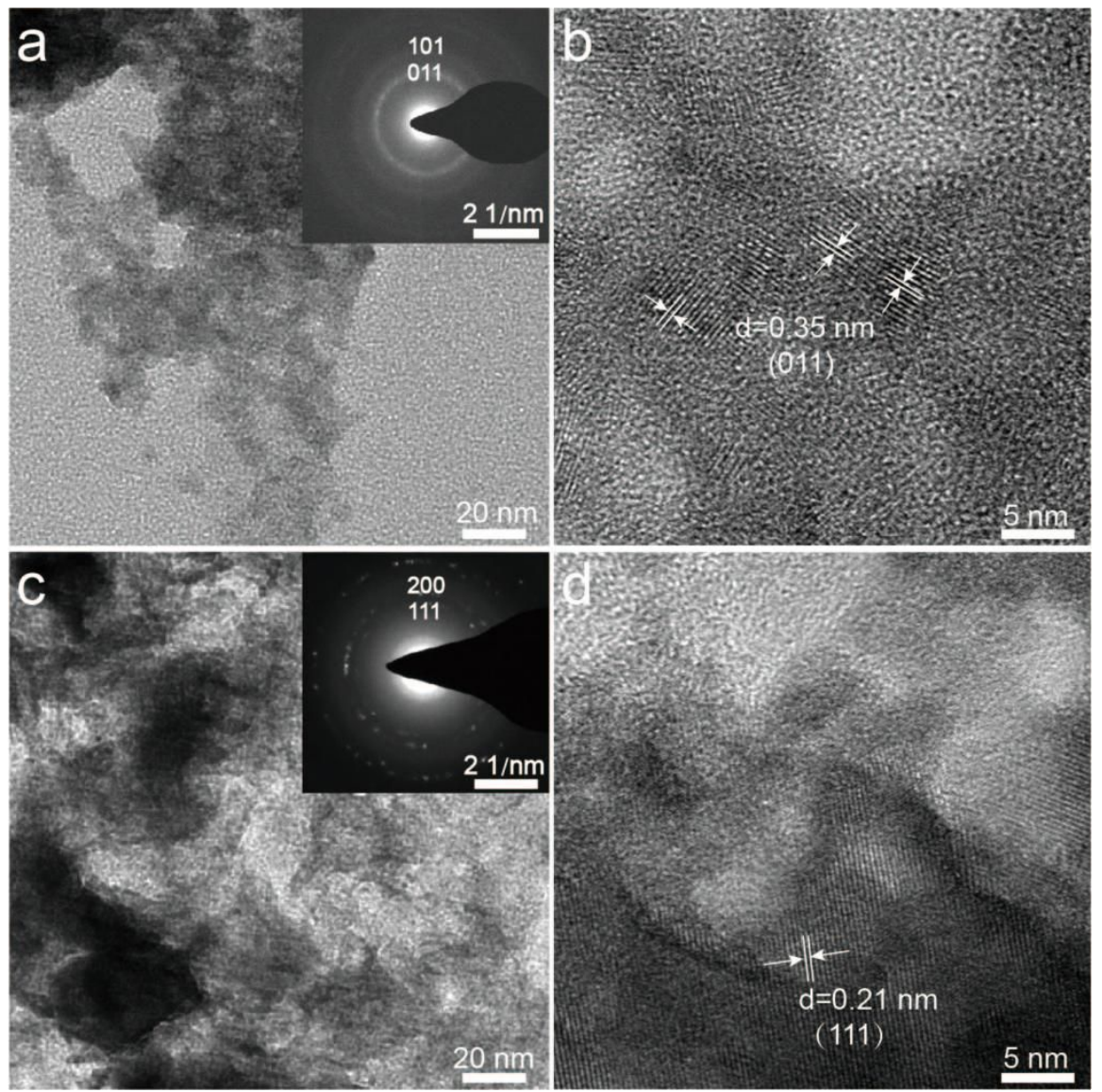

Figure S3. Low-magnification TEM images of bare (a) $\mathrm{WO}_{2}$ and (c) Ni samples, with the corresponding SAED pattern in the insets. HRTEM images of bare (b) $\mathrm{WO}_{2}$ and (d) Ni samples. 

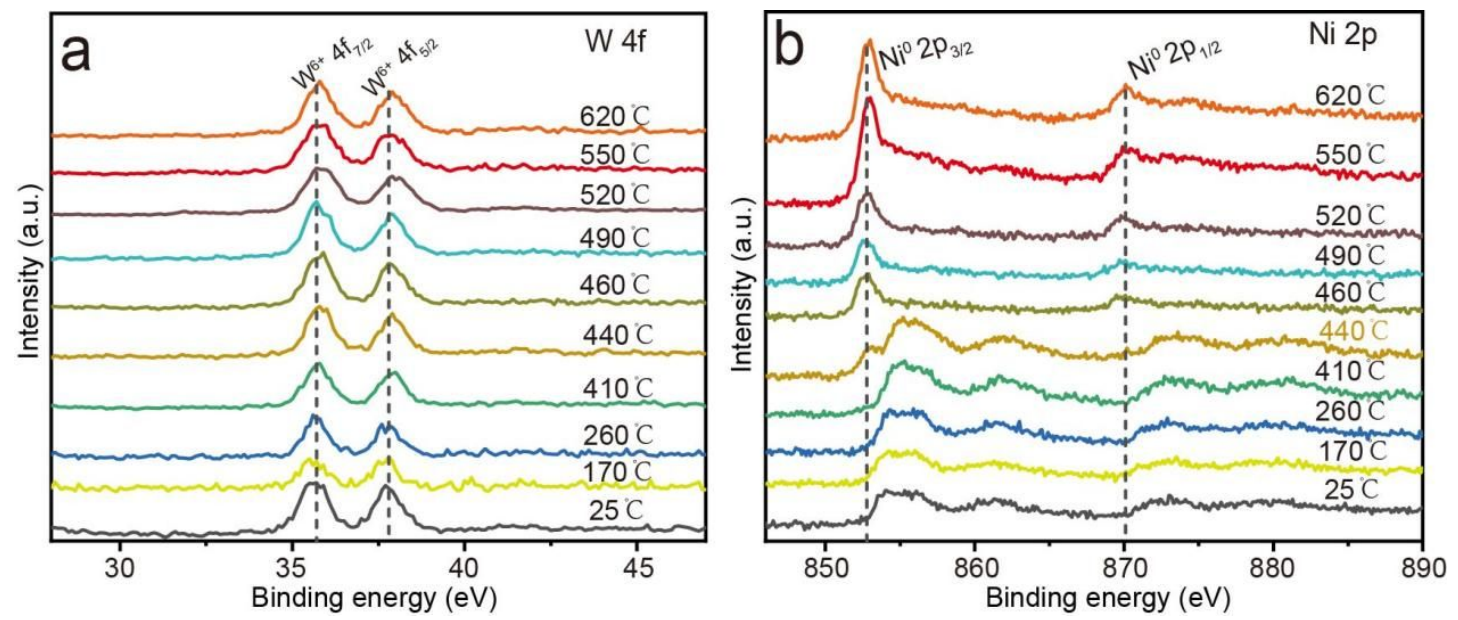

Figure S4. W 4f and Ni $2 p$ core level XPS spectra of $\mathrm{NiWO}_{4}$ treated from room temperature to $620{ }^{\circ} \mathrm{C}$ under Ar atmosphere using the variable-temperature NAP-XPS measurements.

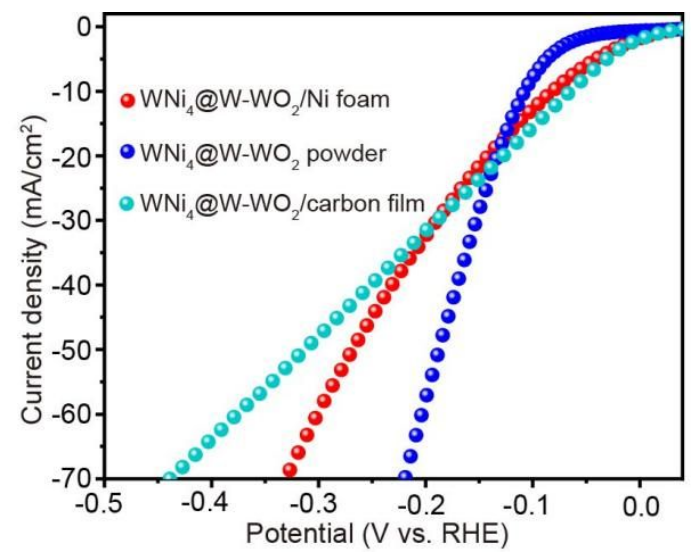

Figure S5. LSV curves of $\mathrm{WNi}_{4} @ \mathrm{~W}-\mathrm{WO}_{2}$ powder loading onto GCE and carbon film in $1 \mathrm{M} \mathrm{KOH}$ electrolyte, with the $\mathrm{WNi}_{4} @ \mathrm{~W}-\mathrm{WO}_{2} / \mathrm{Ni}$ foam as the reference sample. 

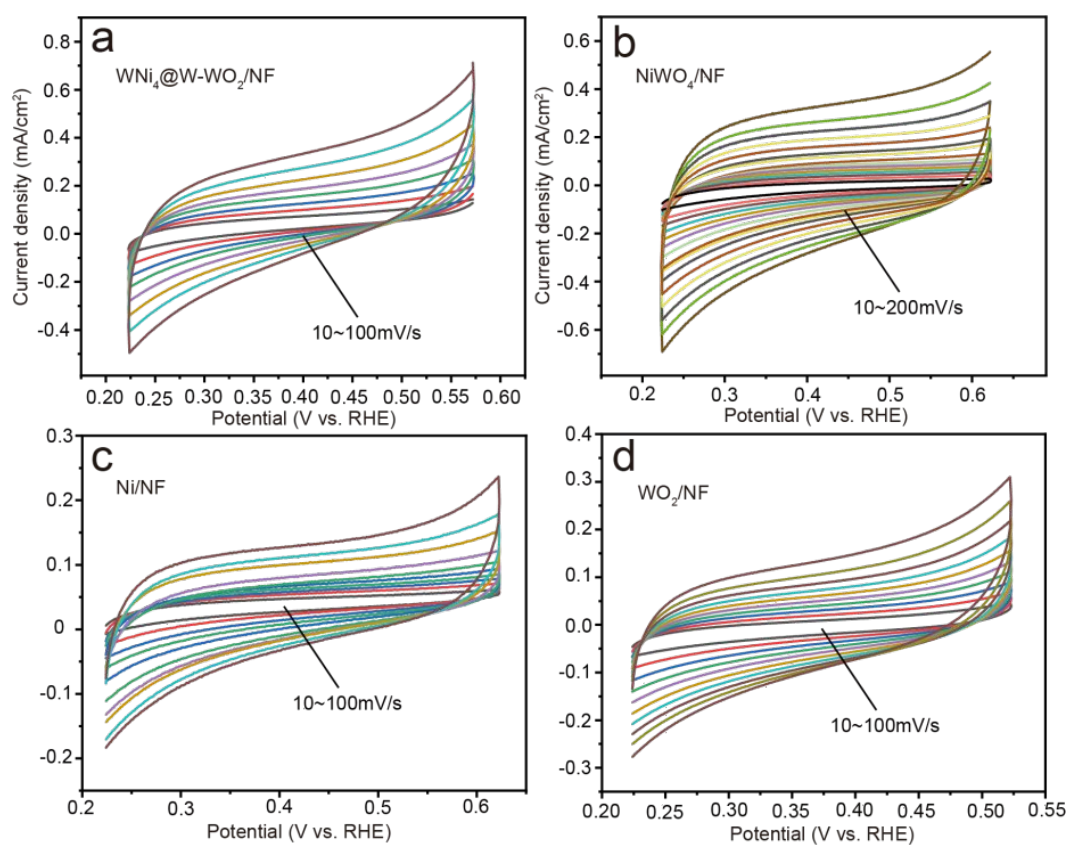

Figure S6. Cyclic voltammetry (CV) curves of(a) $\mathrm{WNi}_{4} @ \mathrm{~W}-\mathrm{WO}_{2} / \mathrm{NF}$, (b) $\mathrm{NiWO}_{4} / \mathrm{NF}$, (c) $\mathrm{Ni} / \mathrm{NF}$, and (d) $\mathrm{WO}_{2} / \mathrm{NF}$ in the region of $0.2-0.6 \mathrm{~V}$ vs. RHE at various scan rates $(10-100 \mathrm{mV} / \mathrm{s})$ in alkaline electrolytes.

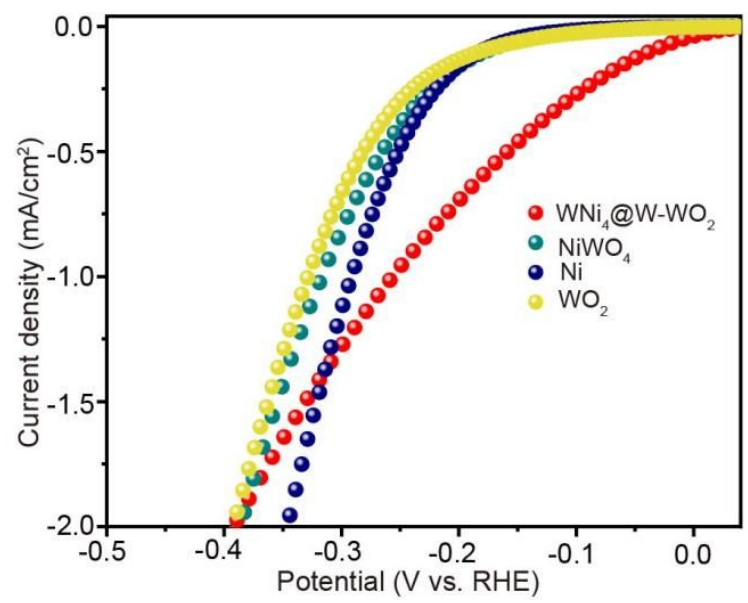

Figure S7. The LSV curves of $\mathrm{WO}_{2}, \mathrm{Ni}, \mathrm{NiWO}_{4}$, and $\mathrm{WNi}_{4} @ \mathrm{~W}-\mathrm{WO}_{2}$ after ECSA normalization. 
Table S1. The relative concentration ratios of the valence-state of $\mathrm{W}$ in $\mathrm{WNi}_{4} @ \mathrm{~W}-$ $\mathrm{WO}_{2}$ at different overpotentials.

\begin{tabular}{cccccc}
\hline$\%$ & Initial & $0 \mathrm{mV}$ & $80 \mathrm{mV}$ & $130 \mathrm{mV}$ & $180 \mathrm{mV}$ \\
\hline $\mathrm{W}^{0}$ & 39.99 & 65.18 & 69.36 & 63.59 & 70.3 \\
$\mathrm{~W}^{4+}$ & 8.47 & 20.64 & 15.69 & 20.51 & 13.18 \\
$\mathrm{~W}^{6+}$ & 51.54 & 14.19 & 14.96 & 15.89 & 16.52 \\
\hline
\end{tabular}

Table S2. The relative concentration ratios of the valence-state of $\mathrm{Ni}$ in $\mathrm{WNi}_{4} @ \mathrm{~W}-$ $\mathrm{WO}_{2}$ at different overpotentials.

\begin{tabular}{cccccc}
\hline$\%$ & Initial & $0 \mathrm{mV}$ & $80 \mathrm{mV}$ & $130 \mathrm{mV}$ & $180 \mathrm{mV}$ \\
\hline $\mathrm{Ni}^{0}$ & 31.11 & 23.48 & 22.91 & 18.39 & 16.17 \\
$\mathrm{Ni}^{2+}$ & 22.95 & 25.75 & 20.95 & 22.18 & 26.04 \\
$\mathrm{Ni}^{3+}$ & 20.15 & 20.65 & 27.38 & 29.26 & 32.61 \\
\hline
\end{tabular}

